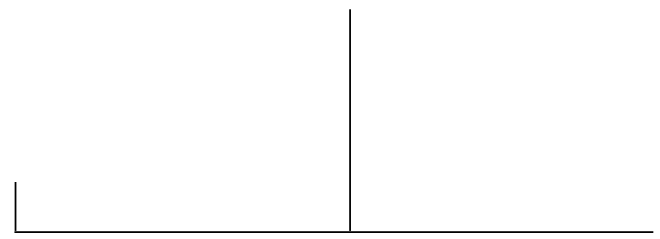

Rev. Latinoam. Psicopat. Fund., São Paulo, v. 13, n. 4, p. 648-651, dezembro 2010

\title{
Medicina não é ciência exata: as relações entre o chavão e os modos de formar de um médico, segundo uma escola dos EUA
}

Mônica Teixeira

O artigo para o qual Observando a Medicina chama atenção neste número da Revista - "Desafio aos requisitos pré-médicos tradicionais como indicadores de sucesso na Escola de Medicina: o Programa Humanidades e Medicina da Escola de Medicina Monte Sinai" - foi publicado em agosto de 2010 na Academic Medicine, órgão oficial (com revisão por pares) da Association of American Medical Colleges. O programa referido no título Programa Humanidades e Medicina da Monte Sinai - foi instituído em 1987 e abre a alunos que tenham optado por diplomas em humanidades ou ciências sociais durante o college a possibilidade de ingresso mediante um sistema de seleção especial que não inclui o exame convencional para ingresso em cursos de medicina, o Medical College Admission Test. O MCAT avalia conhecimentos em química geral e orgânica, física e biologia que, desde 1930, são considerados requisitos mínimos para quem está no college e quer entrar em uma escola de medicina nos EUA.

Ambos os autores do artigo, os médicos David Muller e Nathan Case, são professores da Monte Sinai e ligados ao programa. Sua concepção mostra que, já em 1987, havia o anseio, hoje disseminado nas escolas de medicina, por atrair estudantes de formação mais abrangente. Mas que desempenho tiveram es- 
tes alunos, que ingressaram em uma das mais conceituadas escolas de medicina dos EUA por uma porta lateral, sem passar pelo MCAT? Respondem os autores na conclusão: "Estudantes sem a preparação pré-médica tradicional tiveram desempenho equivalente ao alcançado por seus colegas de classe".

Para chegar a essa afirmação, os professores estudaram resultados alcançados pelos 85 alunos que ingressaram na Escola por meio do Programa Humanidades e Medicina, em comparação aos 606 que entraram pelo caminho convencional - no período 2004-2009. A escolha do período, explicam, se deu pelo fato de, a partir de 2004, ter sido introduzido um sistema de avaliação "que identifica e quantifica todos os aspectos do desempenho dos estudantes". Intitulado Medical Student Performance Evaluation (MSPE), o sistema oferece informações sobre "base de conhecimento científico, performance clínica, liderança e serviço à comunidade, humanismo e profissionalismo, pesquisa/bolsas, e escolha da carreira na residência" - de acordo com o artigo. Além da disponibilidade do MSPE, outra razão para a escolha do período, segundo o artigo, é o número sempre crescente de alunos do Programa entre os formandos a partir de 2004.

$\mathrm{O}$ artigo informa o leitor que os requisitos ainda hoje exigidos do estudante que quer ingressar em um curso de medicina nos EUA - e em países sob sua influência - se consolidaram há oitenta anos. O relatório Flexner, organizado pela Fundação Carnegie, e publicado em 1910, recomendou que o candidato a estudar medicina deveria cumprir requisitos mínimos durante o college; nos vinte anos seguintes, esses requisitos se consolidaram na seguinte forma: um semestre de química orgânica, dois semestres de química geral, dois de física, dois de biologia. A partir de 1981, conta o artigo, a contrariedade, já de décadas, com a "estreiteza dessas exigências", levou a Associação Médica Americana a constituir um grupo de discussão sobre "Educação Profissional Geral do Médico e Preparação para Medicina no College", em que tiveram assento, no relato do artigo, "presidentes de colleges, diretores de escolas de medicina, chefes de departamento, professores de ciência e liberal arts, e médicos". Esse grupo preparou o relatório "Médicos para o século XXI", publicado em 1984, que recomendava tornar mais abrangente a preparação para a escola de medicina e mudar os requisitos de ingresso.

Os autores observam que o grupo de 1981 foi o primeiro a "formalmente reconhecer a existência de uma "sindrome pré-médica" - que impediria a aplicação, pelos médicos, de valores que chamam de humanísticos à prática de uma "profissão dedicada ao cuidado e à cura". Haveria três categorias de opositores aos requisitos tradicionalmente estabelecidos: aqueles que "eliminariam todas as exigências", aqueles que defendiam a "atualização permanente do currículo prémédico", e aqueles que acreditavam em "alargar o currículo de forma a refletir uma educação mais rica em liberal arts". Apesar dessas opiniões, contam os au- 


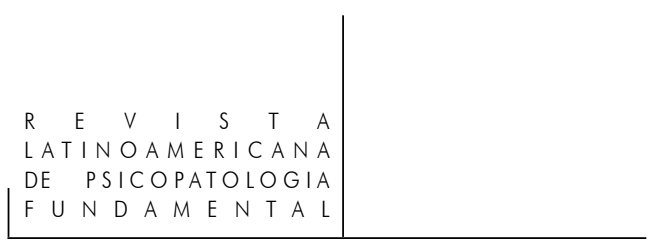

tores, em 2009 mais de $80 \%$ dos estudantes interessados em seguir Medicina apresentaram diplomas fora da área de humanidades e ciências sociais. A melhor forma de conseguir uma vaga em um curso de medicina continuava sendo um resultado excepcional no MCAT.

Para os autores, o problema com a exigência de notas excepcionalmente altas no MCAT, com ênfase em química, física e biologia, é levar para as escolas de medicina alunos que não tiveram a possibilidade de ter contato com uma educação mais abrangente. A expressão "liberal arts" designa cursos de literatura, filosofia, artes, letras clássicas; mas não é apenas a frequência a classes nesses temas que os autores acreditam necessária para o futuro médico. Há também no artigo uma crítica à forma de estudo e de aquisição das habilidades para alto desempenho no MCAT - que levaria a um afastamento do prazer da descoberta científica; o fim da curiosidade científica; à ideia de que a ciência é estática. Além disso, a ideia é alunos que tenham maior variedade de experiências durante o college - o que inclui serviços comunitários, por exemplo - serão melhores médicos no futuro. Por isso, explicam os autores, o Programa estabelece uma nota pequena - 3,5 - como a média mínima que exige de seus selecionados durante os anos no college.

Nas regras do programa Humanidades e Medicina, o aluno de humanidades que se interessar pela Monte Sinai pode dar início a seu processo de seleção no primeiro ou no segundo ano do college. O programa preconiza que a análise inclua resultados do ensino médio e do college, apresentação de dois ensaios, três cartas de recomendação, pontuação mínima no exame SAT (similar ao nosso ENEM) e duas entrevistas na Escola de Medicina. Se aceitos, é necessário que cursem biologia e química geral, com nota mínima B; são convocados a participar de um curso de verão na escola, no qual toma contato com as especialidades médicas e participa de seminários em assuntos como ética médica e saúde pública; e também assistem a um "curso abreviado" de química orgânica e física ligadas a temas de medicina. A Monte Sinai não quer saber de aluno apressado: encoraja que, depois de se formarem no college, os alunos esperem um ano antes de se matricularem - para que eles pensem se querem mesmo ser médicos. $\mathrm{O}$ artigo também conta que nos três meses que antecedem o início de suas aulas no curso de Medicina, a Monte Sinai oferece aos alunos do Programa Humanidades um "Summer Enrichment Program”, de participação voluntária. Em geral, 3/4 dos ingressantes participam dos cursos de bioquímica, anatomia, embriologia, fisiologia celular. Não há provas durante esse programa, só autoavaliação.

A comparação dos resultados mostra diferenças pequenas, "estatisticamente não significativas", no desempenho de um e do outro grupo. Entre os alunos do Programa, houve tendência maior para a escolha de psiquiatria e clínica geral 
na residência; maior probabilidade de notas menores na primeira etapa do USMLE, e tendência maior para um pedido de trancamento de matrícula por dificuldades. Os autores também encontraram número igual de alunos graduados com distinção em pesquisa, em relação aos alunos com formação convencional.

A ideia que fundamenta o programa Humanidades e Ciência, e a forma pela qual a Monte Sinai se propôs a realizá-la, comunica-se com a tendência crítica à transformação do médico em títere da "ciência" - entendida como dona da verdade -, um seu escravo e servidor. Observando a Medicina alegra-se com a existência da ideia e do programa, e com sua permanência nos últimos 13 anos.

Citação/Citation: TeIXeIRA, M. Medicina não é ciência exata: as relações entre o chavão e os modos de formar de um médico, segundo uma escola dos EUA. Revista Latinoamericana de Psicopatologia Fundamental, São Paulo, v. 13, n. 4, p. 648-651, dez. 2010.

Editor do artigo/Editor: Mônica Teixeira e Prof. Dr. Erney Plssmann de Camargo

Recebido/Received: 6.7.2010/7.6.2010 Aceito/Accepted: 25.9.2010/9.25.2010

Copyright: (C) 2009 Associação Universitária de Pesquisa em Psicopatologia Fundamental/ University Association for Research in Fundamental Psychopathology. Este é um artigo de livre acesso, que permite uso irrestrito, distribuição e reprodução em qualquer meio, desde que o autor e a fonte sejam citados/This is an open-access article, which permits unrestricted use, distribution, and reproduction in any medium, provided the original author and source are credited.

Financiamento/Funding: A autora declara não ter sido financiada ou apoiada/The author has no support or funding to report.

Conflito de interesses/Conflict of interest: A autora declara que não há conflito de interesses/The author declares that has no conflict of interest.

\section{MônICa TeIXeIRA}

Jornalista; psicanalista; coordenadora geral do programa Universidade Virtual do Estado de São Paulo na TV Cultura (São Paulo, SP, Brasil); diretora de redação do boletim eletrônico Inovação Unicamp (Campinas, SP, Brasil).

Av. Higienópolis, 318/13

01238-001 São Paulo, SP, Brasil

e-mail: armonica@uol.com.b 